\title{
Molecular Biomethods Handbook
}

\section{(2nd Edn., Walker, J., and Rapley, R. (eds.), Humana Press, New Jersey, 2008, 1124 p., \$109)}

DOI: $10.1134 / \mathrm{S} 0006297909090168$

This book consists of two parts and includes 60 chapters, which cover nucleic acids, proteins, and cell biology methods.

First part highlights nucleic acid (NA) methods and includes 22 chapters.

In the first four chapters basic tools and techniques for manipulation of NA, restriction enzymes, polymerase chain reaction including their application in clinical research, probe design, production, and applications are discussed.

Chapters 5-8 highlight respectively several important methods for NA analysis: Southern blotting, capillary electrophoresis, denaturing HPLC, and gradient gel electrophoresis.

Chapters 9-12 deal with polymorphism of NA and particularly with quantification of mRNA and DNA.

In chapters 13-17, various aspects of hybridization are considered.

Chapters 18-22 are devoted to mapping techniques, cDNA microarrays, single nucleotide polymorphism, and gene/protein sequence analysis.

The second part of the book consists of 38 chapters covering protein and cell methods. The analytical techniques begin with characterization of protein electrophoresis, blotting, autoradiography, and fluorography.
Separate chapters cover mass spectrometry of proteins and peptides, methods for analysis of posttranslational protein modifications, and protein-protein interactions including glycoprotein analysis.

Other basic analytical methods such as ion-exchange, size-exclusion, hydrophobic, and affinity chromatography are described liberally and precisely in separate chapters.

Dedicated chapters of this part deal with amino acid analysis, surface plasmon resonance, macromolecular crystallography, and microchip devices for bioanalysis.

Cell methods represented by mammalian and plant tissue culture, stem cells, magnetic resonance imaging, and electron, confocal, and immunomicroscopy are discussed. Also several chapters of this part cover laser microdissection, flow cytometry, in situ hybridization, and high throughput screening.

Written by experts in their fields, the book gives a wide scope of molecular biology experimentation really living out only the most specialized uncommon techniques while at the same time giving reference to each chapter and sharing full information with readers.

This handbook is suitable for research scientists, technicians, and graduate research students in molecular and cell biology, proteomics, and related branches of science. 